\title{
Rationale for the formulation of fortified detox biscuits
}

\author{
Natalya Sokol $^{1}$, Lyudmila Donchenko ${ }^{1}$, Nadezhda Sanzharovskaya ${ }^{1 *}$, Olga Khrapko ${ }^{1}$, and \\ Eleonora Shepelenko ${ }^{1}$ \\ ${ }^{1}$ Kuban State Agrarian University, 13, Kalinina street, Krasnodar, 350044, Russia
}

\begin{abstract}
Nowadays, most manufacturers are strategically focused on making healthy food products. Flour confectionery is a promising group of food products in this respect. The expansion of the range of flour products is due to the introduction of additional raw materials, one of the options for which is pectin. The aim of the research is to study the effect of different types of pectin on the detoxifying properties of biscuits and their quality indicators. The objects of research are three types of pectin (beet, apple, watermelon) and samples of butter biscuits. In the course of the work, generally accepted methods were used. The influence of the type and dosage of pectin on the quality of butter biscuits has been determined. It has been experimentally proven that the complexing ability of butter biscuits depends on both the type of pectin and its dosage. Cookies with the addition of beet pectin when kneading the dough have a greater complex-forming ability. The optimal dosage of pectin was established $0.3 \%$ to the flour mass. The results obtained show that the addition of pectin to the recipe for butter biscuits improves its quality indicators, allows you to remove xenobiotics from the human body.
\end{abstract}

\section{Introduction}

The main trend in the development of modern society is the growing interest in healthy food products. Changing living conditions, deterioration of the ecological situation dictate the need to provide the population in almost all regions of the world with high-quality and safe food. At the same time, not only nutritional value, physical and economic accessibility, but also a functional orientation in the prevention of socially significant diseases, detoxification, and protection from negative environmental influences are considered as improved characteristics of food products [1-2].

In solving the problem of providing the population with food for dietary, prophylactic purposes, the release of food products enriched with dietary fiber, namely pectin substances, is of great importance [3-4].

Pectin substances remove from the human body almost any kind of toxins associated with pollution and contamination of the environment, and are classified as effective therapeutic and prophylactic enterosorbents [5-6].

\footnotetext{
* Corresponding author: hramova-n@mail.ru
} 
Natural sources of pectin are diverse. Depending on the usage of plant material, pectins are classified according to the degree of esterification. If the degree of esterification is $50 \%$ or more, pectin is considered highly esterified, below 50\%, low esterified. Low ester pectins are good complexing agents and can function as a detoxifier.

The products that are consumed daily and everywhere by all groups of children and adults include bakery, pasta, flour confectionery, and therefore must be enriched first of all [7].

Biscuits, depending on the recipe and cooking method, are divided into several types. Sugar cookies - characterized by significant porosity, fragility and wetness. Hard biscuits characterized by lamination, less brittleness and wetness, contains less sugar and fat than sugar cookies. Butter biscuits - they are produced in the most diverse forms, small sizes, from dough, varied in its properties and containing a large amount of sugar, fat and egg products. In the production of various types of biscuits, dough is the main initial semifinished product, therefore, it is important to study the effect of fortifying additives on the quality of dough and finished products [8].

The purpose of this research work was to study the effect of different types of pectin on the detoxifying properties of biscuits and their quality indicators, as well as to develop formulations for the studied types of pectin.

The research objectives were as follows:

- study of the influence of the type and dosage of pectin on the quality indicators of biscuits;

- development of a mathematical model of the technological process for obtaining biscuits with pectin;

- development of recipes for biscuits with high detoxifying properties.

\section{Objects and methods of research}

The experimental part of the work was carried out in the laboratories of the Department of Storage Technology and Processing Plant Products at Kuban State Agrarian University named after I.T. Trubilina (Russia).

The objects of the study were baking wheat flour of the first grade, pectin: beet, apple, watermelon (obtained in laboratory conditions); prototypes of butter cookies.

The analytical characteristics of pectin were determined by conductometric titration [9]. The studied pectins had a fairly high content of free carboxyl groups. Their number was in the range of $3.15-4.25 \%$. The content of neutralized and esterified carboxyl groups was $1.2-1.3 \%$ and $3.75-3.92 \%$, respectively. These functional groups determine the belonging of pectins to the group of low esterification, which was confirmed by the experimental values of the degree of esterification, which in the experimental samples was from $45-49 \%$. The content of methoxyl groups in all types of pectin is high, 8.9-12.47\%, which allows us to conclude that the studied pectins have high complexing properties. According to the complexing ability, the prototypes of pectin were distributed in the following order:

$$
\begin{aligned}
& \text { Beet } \rightarrow \text { Watermelon } \rightarrow \text { Apple } \\
& \text { reduction of the complexing ability }
\end{aligned}
$$

Flour was evaluated by organoleptic and physicochemical parameters. Baking wheat flour of I grade used as the main raw material for kneading the dough had the characteristics presented in Table 1 . 
Table 1. Physical and chemical characteristics of flour quality.

\begin{tabular}{|c|c|c|c|c|c|c|}
\hline Object of study & $\begin{array}{c}\text { Moisture, } \\
\%\end{array}$ & $\begin{array}{c}\text { Ash } \\
\text { content, } \\
\%\end{array}$ & $\begin{array}{c}\text { Acidity, } \\
{ }^{\circ} \mathrm{H}\end{array}$ & $\begin{array}{c}\text { Mass } \\
\text { fraction of } \\
\text { gluten, } \\
\%\end{array}$ & $\begin{array}{c}\text { Quality } \\
\text { gluten free, } \\
\text { (Fiber } \\
\text { Deformation } \\
\text { Measurement) }\end{array}$ & $\begin{array}{c}\text { Flour gas- } \\
\text { generating } \\
\text { ability (GOS), } \\
\text { ml }\end{array}$ \\
\hline $\begin{array}{c}\text { Baking wheat } \\
\text { flour of the I } \\
\text { grade }\end{array}$ & 13.3 & 0.72 & 2.60 & 30.56 & 89.50 & 800 \\
\hline
\end{tabular}

The quality of finished products was judged by indicators: moisture, alkalinity, wetness, sugar and fat content [10]. The mass fraction of total sugar was determined by the ferricyanide method, the mass fraction of fat was determined by the refractometric method.

Determination of the complexing ability of biscuits is concluded in the treatment of a colloidal solution of biscuits with a standard lead solution. The precipitated $\mathrm{Pb}$-pectates after wet combustion were analyzed for the amount of absorbed lead trilonometrically.

\section{Results}

The high complexing ability of the prototypes of pectin (beet, watermelon, apple) made it possible to make a decision on their use for the production of biscuits with high detoxifying properties.

To develop a recipe for fortified biscuits with high detoxifying properties, a unified recipe for Krimulda shortbread cookies was chosen and presented in Table 2.

Table 2. Recipe for cookies "Krimulda".

\begin{tabular}{|c|c|c|c|c|c|}
\hline \multirow{3}{*}{$\begin{array}{c}\text { Name of raw } \\
\text { materials }\end{array}$} & \multirow{3}{*}{$\begin{array}{c}\text { Mass } \\
\text { fraction of } \\
\text { dry } \\
\text { substances } \\
\% \\
\%\end{array}$} & \multicolumn{4}{|c|}{ Consumption of raw materials, $\mathrm{kg}$} \\
\hline & & \multicolumn{2}{|c|}{ For loading } & \multicolumn{2}{|c|}{$\begin{array}{c}\text { for } 1 \text { ton of finished products } \\
\text { (without } \\
\text { wrapping materials) }\end{array}$} \\
\hline & & $\begin{array}{c}\text { Physical } \\
\text { count }\end{array}$ & $\begin{array}{c}\text { Dry } \\
\text { substance }\end{array}$ & $\begin{array}{c}\text { Physical } \\
\text { count }\end{array}$ & Dry substance \\
\hline Wheat flour 1 grade & 85.50 & 99.70 & 85.24 & 646.35 & 552.63 \\
\hline Powdered sugar & 99.85 & 33.00 & 32.95 & 213.93 & 213.61 \\
\hline Butter & 84.00 & 42.50 & 35.70 & 275.51 & 231.43 \\
\hline Salt & 96.50 & 0.37 & 0.36 & 2.40 & 2.32 \\
\hline Drinking soda & 50.00 & 0.46 & 0.23 & 3.00 & 1.50 \\
\hline Ammonium salt & - & 0.27 & - & 1.77 & - \\
\hline Lemon essence & - & 0.23 & - & 1.49 & - \\
\hline Total & - & 176.77 & 154.74 & 1148.38 & 1005.26 \\
\hline Output & 95.50 & 153.93 & 147.003 & 1000.00 & 955.0 \\
\hline
\end{tabular}

For creation of cookies with detoxifying properties, we studied the influence of prototypes of pectin (beet, watermelon, apple) and their dosage on the quality indicators of butter cookies. The dosage of pectin in the dough recipe was introduced in an amount of $0.1-0.5 \%$ by weight of flour.

The influence of the type and dosage of pectin substances on the quality indicators of butter biscuits was carried out by the method of test laboratory baking, followed by an assessment of their quality.

The results of studies on the effect of the dosage of beet pectin on the quality indicators of butter cookies such as moisture, alkalinity, mass fraction of total sugar, mass fraction of fat and wetness are presented in Table 3. 
Table 3. Influence of the dosage of beet pectin on the quality indicators of cookies.

\begin{tabular}{|c|c|c|c|c|c|c|}
\hline \multirow{2}{*}{ Indicators } & \multirow{2}{*}{ Control } & \multicolumn{5}{|c|}{ Pectin dosage, \% } \\
\cline { 3 - 7 } & 4.80 & 0.1 & 0.2 & 0.3 & 0.4 & 0.5 \\
\hline Moisture, \% & 0.6 & 0.6 & 4.68 & 4.65 & 4.49 & 4.32 \\
\hline Alkalinity, degree & 21.15 & 21.54 & 21.75 & 21.96 & 22.01 & 22.10 \\
\hline $\begin{array}{c}\text { Mass fraction of } \\
\text { total sugar, \% }\end{array}$ & 22.96 & 23.10 & 23.18 & 23.25 & 23.32 & 23.40 \\
\hline $\begin{array}{c}\text { Mass fraction of fat, } \\
\%\end{array}$ & 135.00 & 142.50 & 143.42 & 144.06 & 145.80 & 146.97 \\
\hline Wetness, \% & & \multicolumn{7}{|c|}{}
\end{tabular}

Table 4 presents the results of studies on the effect of dosages of watermelon pectin on the quality characteristics of butter biscuits.

Table 4. Influence of the dosage of watermelon pectin on the quality indicators of butter cookies.

\begin{tabular}{|c|c|c|c|c|c|c|}
\hline \multirow{2}{*}{ Indicators } & \multirow{2}{*}{ Control } & \multicolumn{5}{|c|}{ Pectin dosage, \% } \\
\cline { 3 - 7 } & & 0.1 & 0.2 & 0.3 & 0.4 & 0.5 \\
\hline Moisture, \% & 4.88 & 4.79 & 4.76 & 4.74 & 4.53 & 4.40 \\
\hline Alkalinity, degree & 0.6 & 0.6 & 0.6 & 0.6 & 0.6 & 0.6 \\
\hline $\begin{array}{c}\text { Mass fraction of total } \\
\text { sugar, \% }\end{array}$ & 21.05 & 21.51 & 21.76 & 21.97 & 22.03 & 22.11 \\
\hline $\begin{array}{c}\text { Mass fraction of fat, } \\
\%\end{array}$ & 22.96 & 23.14 & 23.17 & 23.29 & 23.30 & 23.39 \\
\hline Wetness, \% & 135.0 & 140.06 & 140.50 & 140.88 & 141.30 & 141.70 \\
\hline
\end{tabular}

The effect of different dosages of apple pectin can be judged by the results of experimental studies given in Table 5 .

Table 5. Influence of the dosage of apple pectin on the quality indicators of cookies.

\begin{tabular}{|c|c|c|c|c|c|c|}
\hline \multirow{2}{*}{ Indicators } & \multirow{2}{*}{ Control } & \multicolumn{5}{|c|}{ Pectin dosage, \% } \\
\cline { 3 - 7 } & & 0.1 & 0.2 & 0.3 & 0.4 & 0.5 \\
\hline Moisture, \% & 4.88 & 4.74 & 4.72 & 4.69 & 4.52 & 4.35 \\
\hline Alkalinity, degree & 0.6 & 0.6 & 0.6 & 0.6 & 0.6 & 0.6 \\
\hline $\begin{array}{c}\text { Mass fraction of total } \\
\text { sugar, \% }\end{array}$ & 21.08 & 21.53 & 21.75 & 21.94 & 22.03 & 22.13 \\
\hline $\begin{array}{c}\text { Mass fraction of fat, } \\
\%\end{array}$ & 22.96 & 23.13 & 23.19 & 23.28 & 23.30 & 23.41 \\
\hline Wetness, \% & 135.0 & 141.78 & 142.01 & 142.16 & 142.95 & 143.82 \\
\hline
\end{tabular}

Since one of the research tasks was to develop a recipe for cookies with high detoxifying properties, it was important to determine the complexing ability of cookies produced with various types of pectin and to identify the type of pectin and its dosage, with a more optimal result of complex formation.

The complexing ability is based on the interaction of the pectin molecule with heavy and radioactive metal ions. Fig. 1 shows the effect of the type and dosage of pectin on the binding of lead ions. 


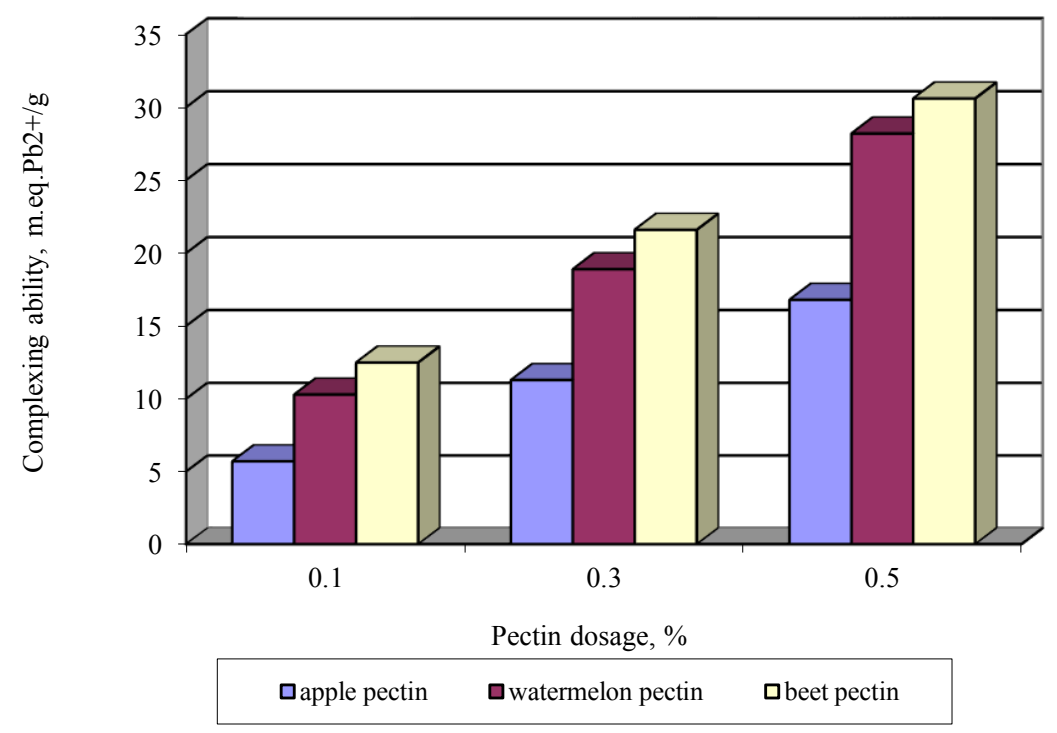

Fig. 1. Influence of the type and dosage of pectin on the complexing ability of cookies.

\section{Discussion}

From tables 3, 4, 5 it can be seen that the moisture content of the cookies, depending on the type of pectin, is different, which is explained by the individual characteristics of the waterholding capacity of the type of pectin. So, $1 \mathrm{~g}$ of beet pectin absorbs $24 \mathrm{ml}$ of water, apple $20 \mathrm{ml}$, and watermelon - $18 \mathrm{ml}$. This explains the high moisture content of biscuits with watermelon pectin compared to biscuits with added watermelon pectin, the moisture content of biscuits will be higher.

With an increase in the dosage of pectin, the moisture content of the cookies decreased, this is due to the fact that pectin has lyophilic properties, that is, it absorbs water, thereby increasing the amount of bound moisture and reducing the amount of free moisture [11].

The alkalinity index in all experimental samples, regardless of the type and dosage of pectin, did not change.

In all experimental samples, there is an increase in the mass fraction of total sugar depending on the dosage, which is probably due to the carbohydrate nature of the pectin substances.

Analysis of the data obtained as a result of determining the mass fraction of fat in the products showed that the type of pectin does not have a significant effect on it, and an increase in dosage in all cases leads to a slight increase in the mass fraction of fat in cookies. This is due to the fact that pectin was introduced instead of the flour mass, that is, the consumption of flour decreased with an increase in the dosage of pectin, and the amount of fat remained unchanged.

The experimental data obtained showed that an increase in the dosage of pectin, regardless of the type of pectin, leads to an increase in the wetting of the biscuits, this can be explained by the functional property of pectin, such as water retention capacity [12].

According to the degree of influence on the structural and mechanical properties of cookies, pectins can be arranged in a row:

beetroot> watermelon> apple.

Determination of the complexing ability index in samples of butter cookies with 
different types of pectin and in different dosages showed that its value depends on the type of pectin and on the dosage used. Figure 1 shows that biscuits with the addition of beet pectin when kneading the dough have a greater complexing ability.

So in the case of the introduction of beet pectin in a dosage of $01 \%$ by weight of flour, the complexing ability was $12.5 \mathrm{~m}$.eq. $\mathrm{Pb}^{2+} / \mathrm{g}$, in the case of adding watermelon pectin 10.3 m.eq. $\mathrm{Pb}^{2+} / \mathrm{g}$, apple pectin -5.7 m.eq. $\mathrm{Pb}^{2+} / \mathrm{g}$. The higher value of the complexing ability index in products with beet pectin compared to watermelon and apple pectin is explained by the high content of free carboxyl groups $\mathrm{COOH}$, on which the complexing ability depends. According to the degree of influence of pectin on the complexing ability of cookies, they are the following: beet, watermelon, apple.

With an increase in the dosage of pectin, regardless of the type, the complexing ability of cookies also increases, as can be seen in Figure 1.

The results of studying the effect of the complexing ability of pectin on the quality parameters of cookies were processed using mathematical methods of analysis.

To study the effect of the complex-forming ability of pectin on the qualitative characteristics of cookies, mathematical methods were used - correlation and regression analyzes, which allow establishing the relationship between the indicators and determining the proportion of the indicators' influence on the dependent variable. The following indicators were taken as independent variables $\left(\mathrm{x}_{1}, \mathrm{x}_{2}, \mathrm{x}_{3}, \mathrm{x}_{4}\right)$ for the calculation: moisture, mass fraction of fat, mass fraction of total sugar, complexing ability. The dependent variable (y) was the cookie wetness rate. The biscuit alkalinity was not scored as the explanatory variable remained unchanged.

As a result of mathematical processing, a relationship was established between the index of the complexing ability of pectin and the qualitative characteristics of the cookie. This relationship is presented in Table 6.

Table 6. The relationship between the complexing ability of pectin and qualitative characteristics.

\begin{tabular}{|c|c|c|c|}
\hline \multirow{2}{*}{ Indicators } & \multicolumn{3}{|c|}{ Pectin type } \\
\cline { 2 - 4 } & beet & apple & watermelon \\
\cline { 2 - 4 } & \multicolumn{3}{|c|}{ Index of correlation } \\
\hline Moisture, \% & -0.94 & -0.94 & -0.92 \\
Mass fraction of total sugar, \% & 0.99 & 0.99 & 0.99 \\
Mass fraction of fat, \% & 0.99 & 0.98 & 0.98 \\
Wetness, \% & 0.97 & 0.88 & 0.90 \\
\hline
\end{tabular}

Table 6 shows that the index of moisture correlation is negative and high, which is explained by the hydrophilic ability of pectin. But the index of correlation of the remaining indicators is positive and also high.

The total indicator that determines the quality of cookies is wetness, therefore it was of interest to study the share of the influence of quality indicators and complexing ability on the wetness of cookies. The proportion of the influence was determined by the method of path analysis. Table 7 shows the proportion of the influence of the mass fraction of fat, mass fraction of total sugar, moisture, complexing ability on the index of the wetness of the cookie.

Table 7. The share of the influence of quality indicators on the wetness of cookies.

\begin{tabular}{|c|c|c|c|}
\hline \multirow{2}{*}{ Indicators } & \multicolumn{3}{|c|}{ Pectin type } \\
\cline { 2 - 4 } & beet & watermelon & beet \\
\hline Moisture, \% & 2.7 & 14.5 & 20.5 \\
Mass fraction of total sugar, \% & 41.1 & 38.4 & 19.7 \\
Mass fraction of fat, \% & 1.2 & 0.3 & 9.4 \\
Complexing ability, & & & 50.4 \\
m.eq. Pb2+/g & 55.0 & 46.8 & \\
\hline
\end{tabular}


The data obtained show that the complexing ability of pectin and, to a greater extent, beet pectin, has a significant effect on the wetness of cookies. For each type of pectin, the proportion of the influence of quality indicators on wetness is different, which is explained by different functional properties of pectins [13-14].

The end result of mathematical processing is the coefficients of the multiple regression equation for the quality of butter biscuits with pectin. The multiple correlation coefficient was calculated, on the basis of which the coefficient of determination $\mathrm{R}^{2}$ was calculated. The coefficient of determination shows how reliable the equation of the mathematical model is. The values of the coefficients of the multiple regression equation for the quality indicators of cookies with pectin are presented in Table 8 .

Table 8. Coefficients of multiple regression equation for quality indicators of cookies with pectin.

\begin{tabular}{|c|c|c|c|c|c|c|}
\hline$a_{0}$ & $\begin{array}{c}\text { Moisture } \\
\mathrm{x}_{1} \\
\% \\
\end{array}$ & $\begin{array}{c}\text { Mass fraction } \\
\text { of fat, } \\
\mathrm{x}_{2}, \\
\% \\
\end{array}$ & $\begin{array}{c}\text { Mass fraction of } \\
\text { total sugar, } \\
\mathrm{x}_{3}, \\
\% \\
\end{array}$ & $\begin{array}{c}\text { Complexing } \\
\text { ability, } \\
\mathrm{x}_{4}, \\
\text { m.eq. } \mathrm{Pb}^{2+} / \mathrm{g}\end{array}$ & \begin{tabular}{|c|} 
Multiple \\
correlation \\
coefficient, \\
$\mathrm{R}$ \\
\end{tabular} & $\begin{array}{c}\text { Coefficient of } \\
\text { determination, } \\
\mathrm{R}^{2}\end{array}$ \\
\hline 393.8 & $\frac{11.7 \%}{-7.82}$ & $\frac{24.8 \%}{-20.14}$ & $\frac{4.42 \%}{11.52}$ & $\frac{34.9 \%}{0.05}$ & 0.87 & 0.76 \\
\hline
\end{tabular}

The numerator contains the share of the indicator's influence on the quality of cookies with pectin, and the denominator contains the coefficients of the regression equation. The first column represents the free term of the equation $\mathrm{a}_{0}$.

Using the regression coefficients, the equation of the mathematical model is compiled (1). This equation is the following:

$$
y=a_{0}-7,82 x_{1}-20,14 x_{2}+11,52 x_{3}+0,05 x_{4}
$$

For a total, the main indicator that affects the quality of cookies with pectin is the complexing ability, which gives grounds to assert about the detoxifying properties of cookies as a result of enrichment with pectin, since it is able to bind and remove heavy metals, radionuclides, carcinogenic and toxic substances from the body. Therefore, cookies with pectin can be used as a product for therapeutic and prophylactic purposes.

For the production of shortbread cookies, enriched with pectin with detoxifying properties, based on the research, formulations were drawn up. The calculation of recipes is made for 1 ton of finished biscuits. For each type of pectin used dosages of $0.1 \% ; 0.2 \%$; $0.3 \% ; 0.4 \% ; 0.5 \%$ by weight of flour.

Compiled formulations are presented in Table 9.

Table 9. Recipes for butter shortbread cookies for each type of pectin.

\begin{tabular}{|c|c|c|c|c|c|}
\hline \multirow{2}{*}{ Name of raw materials } & \multicolumn{5}{|c|}{$\begin{array}{c}\text { Consumption of raw materials for 1 ton of cookies } \\
\text { with pectin dosage, kg }\end{array}$} \\
\cline { 2 - 6 } & \multicolumn{5}{|c|}{ Physical count } \\
\cline { 2 - 6 } & 0.1 & 0.2 & 0.3 & 0.4 & 0.5 \\
\hline Wheat flour I grade & 647.7 & 647.0 & 646.4 & 645.7 & 645.1 \\
Pectin & 0.6 & 1.3 & 1.9 & 2.6 & 3.2 \\
Powdered sugar & 213.9 & 213.9 & 213.9 & 213.9 & 213.9 \\
Butter & 275.5 & 275.5 & 275.5 & 275.5 & 275.5 \\
Salt & 2.4 & 2.4 & 2.4 & 2.4 & 2.4 \\
Drinking soda & 3.0 & 3.0 & 3.0 & 3.0 & 3.0 \\
Ammonium & 1.8 & 1.8 & 1.8 & 1.8 & 1.8 \\
Lemon essence & 1.5 & 1.5 & 1.5 & 1.5 & 1.5 \\
\hline
\end{tabular}


The most optimal dosage that has a positive effect on the quality of the biscuits and gives the cookies detoxifying properties is $0.3 \%$ for any of the studied pectins.

\section{Conclusion}

As a result of the carried out research work, there was studied the influence of the type and dosage of pectin on the quality indicators of butter cookies, recipes for the preparation of butter cookies with pectin were developed.

Three types of pectin were used to make cookies. The influence of each type on the quality indicators of finished products is established.

With the addition of pectin, there was observed a decrease in the moisture content of the biscuits, and, consequently, an increase in wetness, which in general had a positive effect on the quality of the biscuits. With the introduction of pectin, the mass fraction of sugar and fat slightly increased.

With an increase in the dosage of pectin, an increase in its complexing ability in biscuits was observed, which also has a positive effect.

The optimal dosage for all types of pectin has been established $0.3 \%$.

The research results were processed by the method of mathematical statistics, which confirmed the correctness of the chosen direction.

To sum up, it can be concluded that the addition of pectin to butter biscuits not only improves its quality indicators, but also allows you to remove xenobiotics from the human body, which indicates the possibility of using research results in the production of flour confectionery products for therapeutic and prophylactic purposes [15].

\section{References}

1. S. T. Azimova, M. Z. Kizatova, S. O. Akhmetova, et al., Journal of Security and Sustainability Issues, 6 (4), 719-728 (2017)

2. X. Su, F. Wu, Y. Zhang, et al., Food Chemistry, 278, 267-275 (2019)

3. L. V. Donchenko, N. V. Sokol, N. S. Sanzharovskaya, et al., Functional role of pectin in the bakery technology, in Proceedings of Russian Conference on Technological Solutions and Instrumentation for Agribusiness, TSIA 2019, 012010 (2020)

4. N. R. Khule, N. B. Mahale, D. S. Shelar, et al., Der Pharmacia Lettre, 4, 558-564 (2012).

5. L. E. Figueroa, D. B. Genovese, Food Technology and Biotechnology, 56(3), (2018), doi: $10.17113 / \mathrm{ftb} .56 .03 .18 .5641$

6. M. Huda, MOJ Food Process Technol., 2(1), 31-38 (2016), doi: 10.15406/mojfpt.2016.02.00029

7. M. A. Kurek, Food Science and Technology, 40(2), 307-314 (2020), doi.org/10.1590/fst.38318

8. Z. Kohajdova, J. Karovicova, M. Jurasova, Acta Aliment Hung, 42, 91-101 (2013)

9. A. N. Grassino, B. Mladen, D. V. Topic, et al., Food Chemistry, 198, 93-100 (2016)

10. E. V. Korotkaya, I. A. Korotkiy, Foods and Raw Materials, 2, 9-14 (2013)

11. S. Maghaydah, S. A. Hussain, R. Ajo, et al., Food and Nutrition Sciences, 4, 496-502 (2013)

12. L. Liyanage, N. Abidi, D. Auld, H. Moussa, Industrial Crops and Products, 74, 388396 (2015) 
13. H. Herawati, IOP Conf. Series: Journal of Physics: Conf. Series, 1295, 012052 (2019), doi:10.1088/1742-6596/1295/1/012052

14. S. M. Gorlov, N. V. Sokol, O. P. Khrapko, et al., International Journal on Emerging Technologies, 11(2), 314-321 (2020)

15. F. Lyu, S. F. Luiz, D. R. P. Azeredo, et al., Apple Pomace as a Functional and Healthy Ingredient in Food Products: A Review. Processes, 8, 319 (2020), doi:10.3390/pr8030319 